\title{
Simultaneous versus staged surgeries for the treatment of bilateral developmental hip dysplasia in walking age: A comparison of complications and outcomes
}

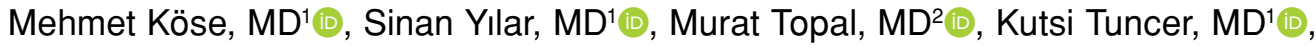 \\ Ali Aydın, MD ${ }^{1}$, Kemal Zencirli, MD(D) \\ ${ }^{1}$ Department of Orthopedics and Traumatology, Atatürk University Faculty of Medicine, Erzurum, Turkey \\ ${ }^{2}$ Department of Orthopedics and Traumatology, Kastamonu University Faculty of Medicine, Kastamonu, Turkey \\ ${ }^{3}$ Department of Orthopedics and Traumatology, Kozluk State Hospital, Erzurum, Turkey
}

The incidence of developmental dysplasia of the hip (DDH) is about 1 to $3 \%$ in newborns, and $20 \%$ of the cases are bilateral.[1] Bilateral cases have both diagnostic and therapeutic challenges in the treatment, as the signs of bilateral DDH is more obscure. ${ }^{[1]}$ This results in late diagnosis of the bilateral DDH cases, which may lead to loss of precious time for conservative management. ${ }^{[2]}$

The main goal of both conservative and surgical treatment is to obtain and maintain a concentric reduction which provides the lowest rate of complications. ${ }^{[3-5]}$ The most common methods in the surgical treatment in cases in which conservative

Received: March 08, 2021

Accepted: October 15, 2021

Published online: November 19, 2021

Correspondence: Sinan Yılar, MD. Atatürk Üniversitesi Tıp

Fakültesi Ortopedi ve Travmatoloji Anabilim Dalı,

25240 Yakutiye Erzurum, Türkiye.

E-mail: sinan_yilar@hotmail.com

Doi: $10.52312 /$ jdrs.2021.38

Citation: Köse M, Yılar S, Topal M, Tuncer K, Aydın A, Zencirli K. Simultaneous versus staged surgeries for the treatment of bilateral developmental hip dysplasia in walking age: A comparison of complications and outcomes. Jt Dis Relat Surg 2021;32(3):605-610.

(อ2021 All right reserved by the Turkish Joint Diseases Foundation

This is an open access article under the terms of the Creative Commons Attribution-NonCommercial License, which permits use, distribution and reproduction in any medium, provided the original work is properly cited and is not used for commercial purposes (http://creativecommons.org/licenses/by-nc/4.0/).

\section{ABSTRACT}

Objectives: This study aims to compare the radiological outcomes and rate of complication between single-stage and staged operation for the treatment of bilateral developmental dysplasia of the hip (DDH).

Patients and methods: A total of 100 patients (13 males, 87 females; mean age: $18.1 \pm 2.1$ months; range, 12 to 36 months) with bilateral DDH who were older than 15 months of age and treated with open reduction $(\mathrm{OR})$ or Pemberton pericapsular osteotomy (PPO) were retrospectively analyzed. Of the patients, 48 were operated with OR and 52 were operated with PPO. Improvements in acetabular indices, presence of avascular necrosis, radiological results, and other complications were noted.

Results: There was no statistically significant difference in the preoperative acetabular indices, range of International Hip Dysplasia Institute (IHDI) classification, follow-up period, and age at the time of operation between the groups $(p>0.05)$. There was no statistically significant difference in the acetabular indices, rate of avascular necrosis, and radiological results at the end of 24 months of follow-up between the groups ( $p>0.05)$.

Conclusion: Our study results show no significant difference in the radiological outcomes and complications between simultaneous and staged surgeries for the treatment of bilateral DDH in children in the walking age.

Keywords: Avascular necrosis, developmental dysplasia of the hip, osteotomy, simultaneous surgery, single-stage.

management cannot be done are open reduction (OR) and Pemberton pericapsular osteotomy (PPO). ${ }^{[4,5]}$

Pemberton pericapsular osteotomy was first described by Paul A. Pemberton for DDH in 1965. ${ }^{[6]}$ Since then, it is one of the osteotomy techniques which is widely preferred by pediatric orthopedic surgeons all over the world. It can be performed until the 
closure of the $\mathrm{Y}$ cartilage in children which is used as a hinge for providing the acetabular coverage of the femoral head to maintain a concentric reduction. ${ }^{[7]}$

As the PPO is an incomplete osteotomy and placement of the graft has intrinsic stability, the PPO can be performed bilaterally at a single-stage surgery. ${ }^{[8]}$ There are limited studies in the literature that can guide decision-making regarding a single-stage or staged surgeries for the management of bilateral DDH. It is reported that single-stage surgery has certain advantages such as less duration of anesthesia, hospitalization, and cost..$^{[9]}$ Most of the studies have compared bilateral cases with unilateral cases with
DDH, except for our previous study, which had bilateral cases in both groups. ${ }^{[10]}$

Bilateral DDH surgery has been performed either in a single stage or two separate stages in our clinic. We usually observe better outcomes in single-stage surgery. In the present study, we aimed to compare the radiological outcomes and rate of complication between single-stage and staged operation for the treatment of bilateral DDH.

\section{PATIENTS AND METHODS}

This single center, retrospective study was conducted at Atatürk University Faculty of Medicine,
Grade 1

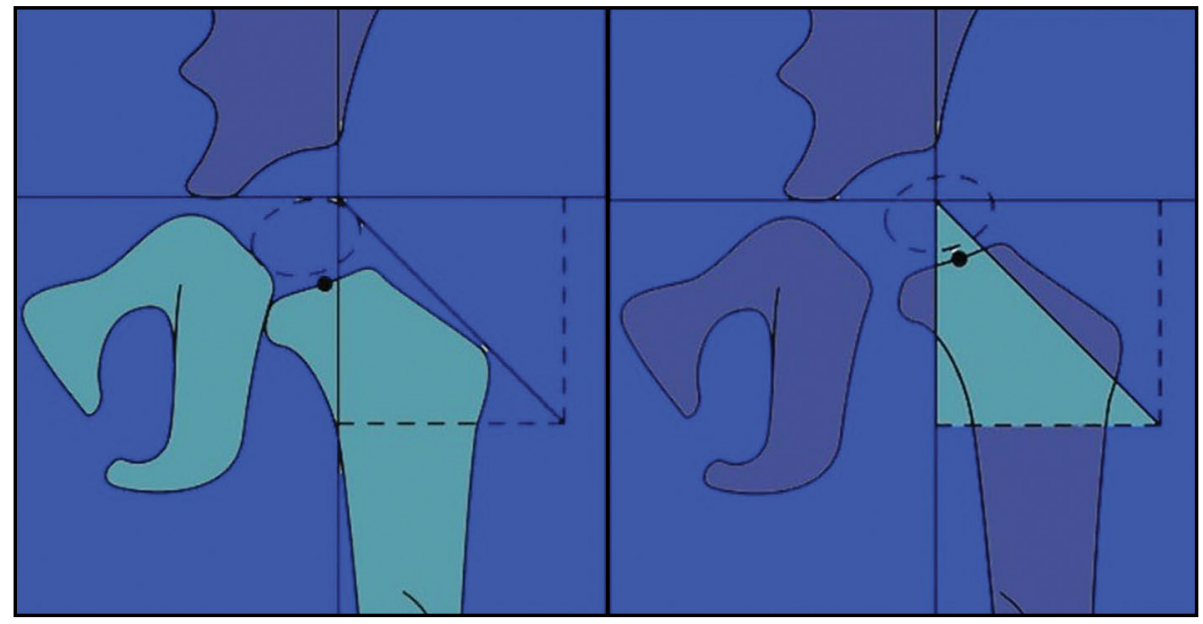

Grade 3
Grade 2

Grade 4

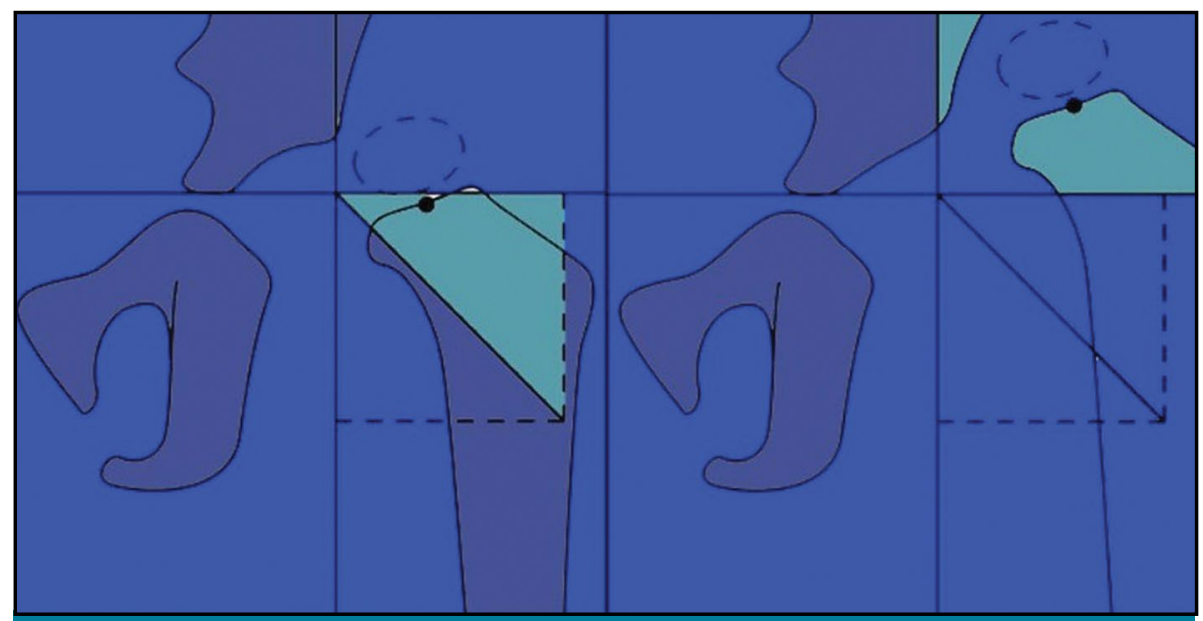

FIGURE 1. International Hip Dysplasia Institute Classification; H-line is Hilgenreiner's line drawn through the top of the tri-radiate cartilages bilaterally. P-line is Perkin's line drawn perpendicular to the $\mathrm{H}$-line at the superolateral margin of the acetabulum. D-line is diagonal line drawn 45 degrees from the junction of $\mathrm{H}$-line and $\mathrm{P}$-line. $\mathrm{H}$-point is the midpoint of the superior margin of the ossified metaphysis. Grade I: the H-point is at or medial to the P-line. Grade II: the H-point is lateral to the P-line and at or medial to the D-line. Grade III: the H-point is lateral to the D-line and at or inferior to the H-line. Grade IV: the $\mathrm{H}$-point is superior to the $\mathrm{H}$-line. 


\begin{tabular}{|cl|}
\multicolumn{3}{c|}{ TABLE I } \\
Kalamchi-MacEwen classification \\
\hline Grade & Definition \\
\hline I & Ossific nucleus mottling and revasuclarizaiton \\
II & Involvement of the epiphysis and lateral physis \\
III & Involvement of the epiphysis and central physis \\
IV & Total involvement of epiphysis and central physis \\
V & Unclassified \\
\hline
\end{tabular}

Department of Orthopedics and Traumatology between January 2010 and December 2018. Initially, 253 patients with bilateral DDH who underwent OR and PPO were screened. Of the patients, 38 with talipes equinovarus, cerebral palsy, and spina bifida were excluded from the study. Patients who were older than 36 months and had additional femoral shortening and/or derotation osteotomies and staged surgeries with a prolonged operation duration and bleeding $(n=56)$ and those who had less than 24 months of follow-up $(\mathrm{n}=59)$ were also excluded. Finally, a total of 100 patients (13 males, 87 females; mean age: $18.1 \pm 2.1$ months; range, 12 to 36 months) with bilateral DDH who were older than 15 months of age and treated with OR or PPO were included. A written informed consent was obtained from each parent and/or legal guardian of the patient. The study protocol was approved by the Atatürk University Faculty of Medicine Ethics Committee (B.30.2.ATA.0.01.00). The study was conducted in accordance with the principles of the Declaration of Helsinki.

All surgeries were performed by two senior surgeons who are experienced in pediatric orthopedics. Preoperative acetabular indices and presence of the ossific nucleus were noted. The patients were classified according to the International Hip Dysplasia Institute (IHDI) ${ }^{[1]]}$ classification system (Figure 1).

Postoperative acetabular indices, presence of avascular necrosis (AVN) according to the KalamchiMacewen classification and radiological evaluation according to the Severin classification (Tables I, II) were evaluated with pelvic anteroposterior X-ray views at the final follow-up. Additional complications were also noted.
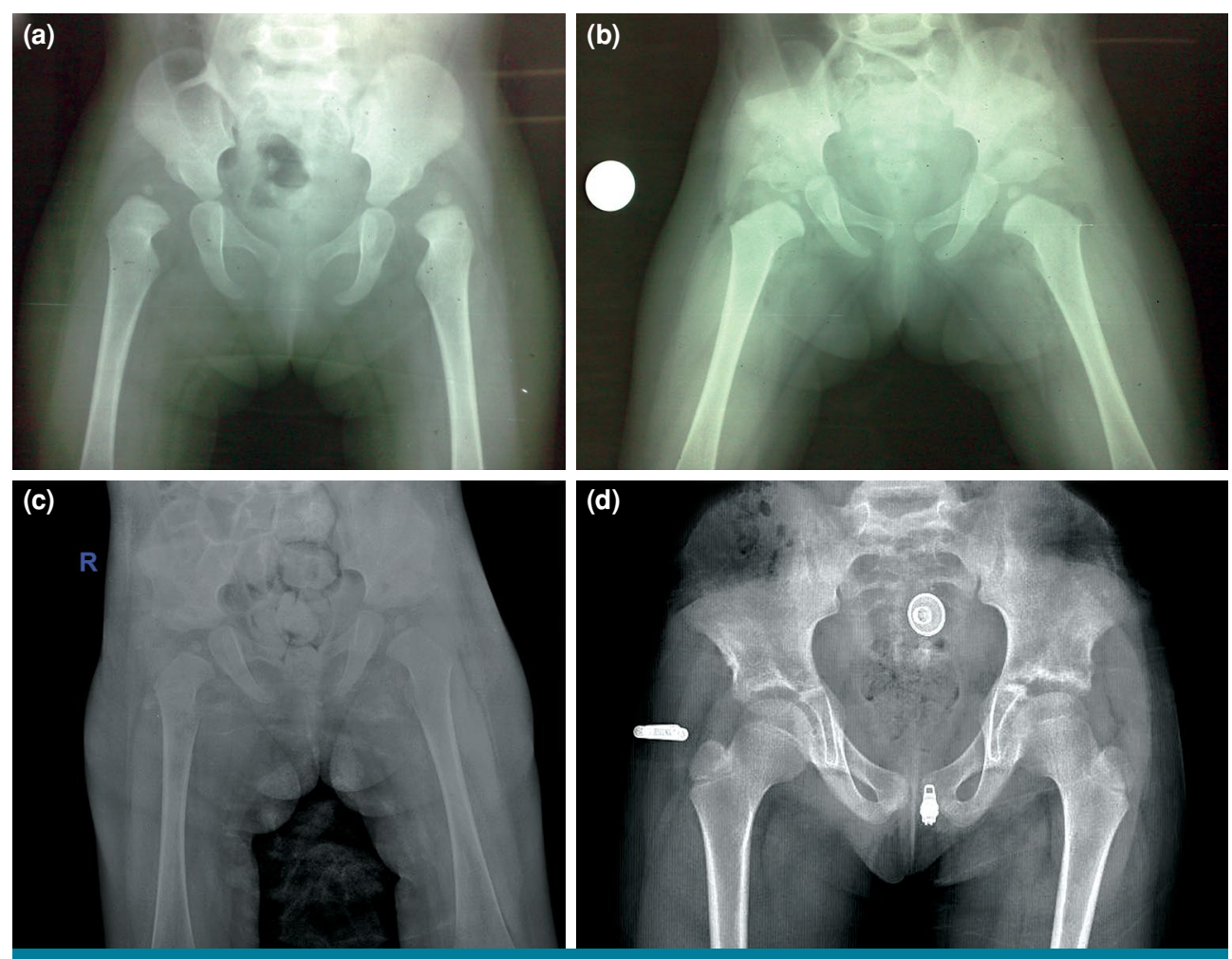

FIGURE 2. Twenty two month old female patient, (a) preoperative AP pelvic view. (b) Perioperative AP pelvic view. (c) Early postoperative AP pelvic view (after cast removal). (d) Postoperative six years follow-up AP pelvic view. 


\begin{tabular}{|c|c|}
\hline & $\begin{array}{c}\text { TABLE II } \\
\text { Severin's radiological classification }\end{array}$ \\
\hline Class & Definition \\
\hline I (perfect) & Normal appearence \\
\hline II (good) & $\begin{array}{l}\text { Mild deformity of the femoral head and neck and } \\
\text { acetabulum }\end{array}$ \\
\hline III (mild) & $\begin{array}{l}\text { Dysplasia or moderate deformity of the femoral head } \\
\text { and neck or the acetabulum, or both }\end{array}$ \\
\hline IV (poor) & Subluxation of the femoral head \\
\hline $\mathrm{V}$ (poor) & $\begin{array}{l}\text { Articulation of the femoral head with a false } \\
\text { acetabulum }\end{array}$ \\
\hline VI (poor) & Rredislocation \\
\hline
\end{tabular}

\begin{tabular}{|c|c|c|c|}
\hline \multicolumn{4}{|c|}{$\begin{array}{l}\text { TABLE III } \\
\text { Comparison of simultaneous an }\end{array}$} \\
\hline & Single stage & Consecutive & \\
\hline & Mean $\pm S D$ & Mean $\pm S D$ & $p$ \\
\hline Preoperative Al & $39.8 \pm 4.8$ & $40.3 \pm 5.1$ & 0.521 \\
\hline Postoperative Al & $12.0 \pm 4.9$ & $12.3 \pm 4.4$ & 0.668 \\
\hline Age (year) & $18.2 \pm 2.1$ & $17.9 \pm 1.9$ & 0.489 \\
\hline Follow-up period & $30.2 \pm 14.7$ & $29.1 \pm 12.7$ & 0.562 \\
\hline
\end{tabular}

\section{Surgical technique}

All patients were operated via the Smith-Petersen approach using the same technique. Open reduction of the hip joint with the removal of the barriers of reduction was done with a staged PPO and closure with capsulorrhaphy. After closure, the spica cast was done in a proper position. The patients were kept in the cast for eight weeks postoperatively. There was one-month interval between the operations in staged surgeries and the patients were also kept in spica cast for two months after the second stage. The patients were kept in nocturnal abduction orthosis in the following month of cast removal and were followed

\begin{tabular}{|c|c|c|c|}
\hline \multicolumn{4}{|c|}{$\begin{array}{c}\text { TABLE IV } \\
\text { Comparison of the groups according to IHDI classification }\end{array}$} \\
\hline \multirow[b]{2}{*}{ Grade } & Single stage & Consecutive & \multirow[b]{2}{*}{$p$} \\
\hline & $n$ & $n$ & \\
\hline 1 & 2 & 0 & \multirow{4}{*}{0.497} \\
\hline II & 56 & 62 & \\
\hline III & 24 & 19 & \\
\hline IV & 14 & 23 & \\
\hline IHDI: Inter & lip Dysplasia & & \\
\hline
\end{tabular}

\begin{tabular}{|c|c|c|c|c|c|}
\hline \multicolumn{6}{|c|}{$\begin{array}{c}\text { Comparison of radiological outcomes of the groups } \\
\text { according to Severin classification }\end{array}$} \\
\hline \multirow[b]{2}{*}{ Grade } & \multicolumn{2}{|c|}{ Single stage } & \multicolumn{2}{|c|}{ Consecutive } & \multirow[b]{2}{*}{$p$} \\
\hline & $n$ & $\%$ & $n$ & $\%$ & \\
\hline I & 61 & 63.5 & 58 & 55.8 & \\
\hline II & 35 & 36.5 & 46 & 44.2 & \\
\hline
\end{tabular}

every two months in the first year and every six months in the second year (Figure 2).

\section{Statistical analysis}

Statistical analysis was performed using the IBM SPSS version 20.0 software (IBM Corp., Armonk, NY, USA). Descriptive data were expressed in mean \pm standard deviation (SD), median (min-max) or number and frequency, where applicable. The Shapiro-Wilk test was used to test for normal distribution of continuous variables. The independent samples t-test and Mann-Whitney $U$ test were used, if the distribution of variables was normal and non-normal, respectively. The comparisons between categorical variables were performed using the chi-square test and Fisher exact test. A $p$ value of $<0.05$ was considered statistically significant.

\begin{tabular}{|lcccccc|}
\hline \multicolumn{7}{c}{ TABLE V } \\
Comparison of the groups according to Kalamchi-McEwen classification
\end{tabular}




\section{RESULTS}

A total of 100 patients who were at the walking age with bilateral DDH were included in the study. Of the patients, 48 were operated in a simultaneous surgery, whereas 52 patients had staged surgery.

Clinical data of the patients are summarized in Table III. The radiological, clinical outcomes, rate of complications of simultaneous and staged surgery groups were compared (Tables 4, 5 and 6). There was no statistically significant difference between the simultaneous and staged surgery groups in terms of the preoperative acetabular indices, IHDI classification, follow-up period, and age during the operation (Table III) $(\mathrm{p}<0.05)$.

In addition, there was no statistically significant difference in the last acetabular indices, rate of AVN, and radiological results at the end of 24 months of follow-up between the groups $(p<0.05)$. One patient in staged surgery group had a supracondylar femoral fracture and two had subtrochanteric femoral fractures after a minor trauma within two months after cast removal. No patient in the simultaneous group had fractures. No other complication was observed in any of the patients.

\section{DISCUSSION}

Pemberton pericapsular osteotomy is a frequently preferred technique in treatment of $\mathrm{DDH}$ with particularly anterior and superolateral insufficiency. ${ }^{[6,12]}$ It has certain advantages such as not causing pelvic instability, limb length discrepancy, and no need for additional fixation. ${ }^{[13]}$ Salter innominate osteotomy provides bilateral single-stage surgery by not using the symphysis pubis as a hinge, while correcting the acetabular index. ${ }^{[8,13,14]}$ As a result of aforementioned properties, PPO has proven to be a safe, reliable option even in simultaneous surgeries. ${ }^{[6,10,14,15]}$ Yilar et al. ${ }^{[10]}$ reported simultaneous PPO to reduce cost and rate of complications with similar outcomes. Still, simultaneous PPO and OR surgery have certain challenges including difficulty for the surgeon due to the prolonged stressful surgery. That is why the simultaneous surgery is advised to be performed by experienced surgeons..$^{[9,10,14]}$

In the literature, treatment of bilateral $\mathrm{DDH}$ yields favorable or similar radiological and clinical outcomes than unilateral cases. Wang et al. ${ }^{[16]}$ compared 56 bilateral cases with 156 unilateral cases and reported $80.4 \%$ satisfactory outcomes in bilateral and $86.5 \%$ in unilateral cases according to the Severin classification. They also reported
$55 \%$ type II or worse AVN in bilateral cases and $38 \%$ or worse AVN in unilateral cases according to the Kalamchi-MacEwen classification and $46 \%$ perfect or good outcomes in bilateral cases and $71 \%$ good or perfect outcomes in unilateral cases according to the McKay classification. There was no significant difference between the groups in terms of the Severin classification, but the unilateral cases had better outcomes according to the KalamchiMacEwen and McKay classifications. Agus et al. ${ }^{[17]}$ compared 12 bilateral cases and 12 unilateral cases who underwent OR + Salter osteotomy in their study. They found no significant difference between the groups regrading the Mac Kay scores and radiological improvements in acetabular indices. Gem et al. ${ }^{[18]}$ also reported type I AVN in 10 cases, type II in two cases, and type IV in two cases according to the Kalamchi-MacEwen classification in their study which reported the outcomes of 46 patients with bilateral DDH. In our study, we found no significant difference between the simultaneous and staged groups in terms of the improvements in acetabular indices, rate of AVN according to the Kalamchi-MacEwen classification, and radiological results according to the Severin classification.

Consistent our findings, a study conducted by Ochoa et. ${ }^{[19]}$ included 90 hips of 45 patients who underwent $\mathrm{OR}$ and innominate osteotomy. Fifteen patients had simultaneous and 30 patients had two consecutive operations. There was no significant difference in the postoperative outcomes between the simultaneous and staged groups. The authors concluded that simultaneous bilateral OR and innominate osteotomies were effective and practical with a better improvement in acetabular indices after simultaneous surgery.

Review of the literature reveals a limited number of studies to guide decision making for simultaneous or staged surgeries in the treatment of bilateral DDH. Most of the studies have a common source of bias that is to compare simultaneous bilateral DDH operations with unilateral cases or staged surgeries..$^{[9,14,16]}$ In this study, we evaluated simultaneous bilateral cases with only bilateral cases who had two staged operations to eliminate bias in patient groups. This study is unique for this aspect and it provides valuable information regarding the comparison of single and staged operations. We found no significant difference in the rates of AVN and acetabular indices.

On the other hand, the main limitation of our study is its retrospective design which prevented us from evaluating other parameters such as the 
psychological effect of surgeries on patients and families. Therefore, further prospective studies with longer follow-ups are needed for a better comparison of simultaneous or staged surgeries.

In conclusion, our study results show no significant difference in the clinical outcomes and complications between simultaneous and staged surgeries for the treatment of bilateral DDH in children in the walking age. Simultaneous surgery can be preferred in clinics experienced in PPO for the treatment of $\mathrm{DDH}$ in children in the walking age.

\section{Declaration of conflicting interests}

The authors declared no conflicts of interest with respect to the authorship and/or publication of this article.

\section{Funding}

The authors received no financial support for the research and/or authorship of this article.

\section{REFERENCES}

1. Morbi AH, Carsi B, Gorianinov V, Clarke NM. Adverse outcomes in infantile bilateral developmental dysplasia of the hip. J Pediatr Orthop 2015;35:490-5.

2. Sewell MD, Rosendahl K, Eastwood DM. Developmental dysplasia of the hip. BMJ 2009;339:b4454.

3. Yılmaz G, Bakırcığlu S, Çetik RM. Effectiveness of abduction orthosis for the treatment of acetabular dysplasia. Eklem Hastalik Cerrahisi 2019;30:32-7.

4. Adanır O, Yüksel S, Beytemur O. A new method for the assessment of reduction tension during open reduction in patients with developmental dysplasia of the hip. Eklem Hastalik Cerrahisi 2019;30:38-45.

5. Kamacı S, Kaymakoğlu M, Ramazanov R, Aksoy MC, Yilmaz G. Preliminary results of rigid fixation (locking plate/screw) after triple pelvic osteotomy without a hip spica cast: A modified fixation method in 21 patients. Jt Dis Relat Surg 2021;32:454-60.

6. Pemberton PA. Pericapsular osteotomy of the ilium for treatment of congenital subluxation and dislocation of the hip. J Bone Joint Surg [Am] 1965;47:65-86.

7. Eyre-Brook AL, Jones DA, Harris FC. Pemberton's acetabuloplasty for congenital dislocation or subluxation of the hip. J Bone Joint Surg [Br] 1978;60:18-24.
8. Utterback JD, MacEwen GD. Comparison of pelvic osteotomies for the surgical correction of the congenital hip. Clin Orthop Relat Res 1974;(98):104-10.

9. Zorer G, Bagatur AE. Cift taraflı gelişimsel kalça displazisinde tek seansta çift taraflı Pemberton perikapsüler osteotomisi. Acta Orthop Traumatol Turc 2002;36:288-94.

10. Yilar S, Topal M, Zencirli K, Köse M, Ezirmik N. Comparison of total cost and outcomes between single-stage open reduction and Pemberton periacetabular osteotomy operation and two separate consecutive operations in treatment of bilateral developmental hip dysplasia in children at walking age. J Pediatr Orthop B 2020;29:256-60.

11. Narayanan U, Mulpuri K, Sankar WN, Clarke NM, Hosalkar $\mathrm{H}$, Price CT; International Hip Dysplasia Institute. Reliability of a new radiographic classification for developmental dysplasia of the hip. J Pediatr Orthop 2015;35:478-84.

12. Herring JA, Tachdjian MO, Children TSRHf. Tachdjian's Pediatric Orthopaedics. 5th ed. Philadelphia: Saunders; 2002.

13. Aydin A, Kalali F, Yildiz V, Ezirmik N, Aydin P, Dostbil A. The results of Pemberton's pericapsular osteotomy in patients with developmental hip dysplasia. Acta Orthop Traumatol Turc 2012;46:35-41.

14. Alsiddiky A, Alatassi R, Alqarni MM, Bakerman K. Simultaneous bilateral single-stage combined open reduction and pelvic osteotomy for the treatment of developmental dysplasia of the hip. J Pediatr Orthop B 2020;29:248-55.

15. Subasi M, Arslan H, Cebesoy O, Buyukbebeci O, Kapukaya A. Outcome in unilateral or bilateral DDH treated with one-stage combined procedure. Clin Orthop Relat Res 2008;466:830-6.

16. Wang TM, Wu KW, Shih SF, Huang SC, Kuo KN. Outcomes of open reduction for developmental dysplasia of the hip: Does bilateral dysplasia have a poorer outcome? J Bone Joint Surg [Am] 2013;95:1081-6.

17. Agus H, Bozoglan M, Kalenderer Ö, Kazımoğlu C, Onvural B, Akan İ. How are outcomes affected by performing a one-stage combined procedure simultaneously in bilateral developmental hip dysplasia? Int Orthop 2014;38:1219-24.

18. Gem M, Arslan H, Ozkul E, Alemdar C, Azboy I, Demirtaş A. One-stage bilateral open reduction using the anterior iliofemoral approach in developmental dysplasia of the hip. Acta Orthop Belg 2014;80:211-5.

19. Ochoa O, Seringe R, Soudrie B, Zeller R. Salter's single-stage bilateral pelvic osteotomy. Rev Chir Orthop Reparatrice Appar Mot 1991;77:412-8. 